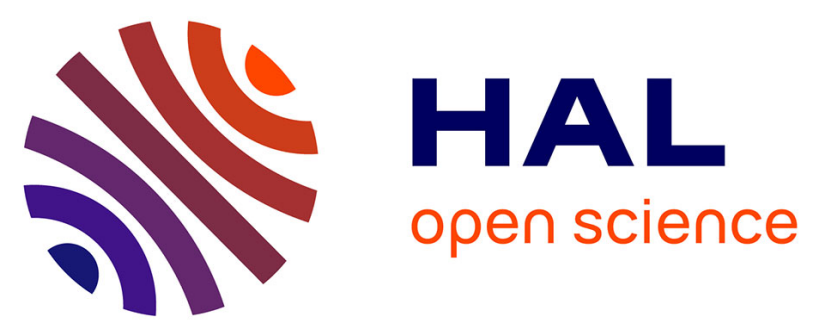

\title{
Results of a phase I study in patients suffering from secondary-progressive multiple sclerosis demonstrating the safety of the amino acid copolymer PI-2301 and a possible induction of an anti-inflammatory cytokine response
}

J. Kovalchin, J. Krieger, M. Genova, K. Collins, M. Augustyniak, A. Masci, T. Hittinger, B. Kuca, Gilles Edan, C. Braudeau, et al.

\section{- To cite this version:}

J. Kovalchin, J. Krieger, M. Genova, K. Collins, M. Augustyniak, et al.. Results of a phase I study in patients suffering from secondary-progressive multiple sclerosis demonstrating the safety of the amino acid copolymer PI-2301 and a possible induction of an anti-inflammatory cytokine response. Journal of Neuroimmunology, 2010, 225 (1-2), pp.153-163. 10.1016/j.jneuroim.2010.04.008 • hal-01874527

HAL Id: hal-01874527

https://hal-univ-rennes1.archives-ouvertes.fr/hal-01874527

Submitted on 20 Sep 2018

HAL is a multi-disciplinary open access archive for the deposit and dissemination of scientific research documents, whether they are published or not. The documents may come from teaching and research institutions in France or abroad, or from public or private research centers.
L'archive ouverte pluridisciplinaire HAL, est destinée au dépôt et à la diffusion de documents scientifiques de niveau recherche, publiés ou non, émanant des établissements d'enseignement et de recherche français ou étrangers, des laboratoires publics ou privés. 


\title{
Results of a phase I study in patients suffering from secondary-progressive multiple sclerosis demonstrating the safety of the amino acid copolymer PI-2301 and a possible induction of an anti-inflammatory cytokine response ${ }^{\text {th }}$
}

\author{
J. Kovalchin a , J. Krieger ${ }^{\text {a }}$, M. Genova ${ }^{\text {a }}$, K. Collins ${ }^{\text {a }}$, M. Augustyniak ${ }^{\text {a }}$, A. Masci ${ }^{\text {a }}$, T. Hittinger ${ }^{\text {a }}$, B. Kuca ${ }^{\text {a }}$, \\ G. Edan ${ }^{\text {b }}$, C. Braudeau ${ }^{\text {c }}$, M. Rimbert ${ }^{\text {c }}$, U. Patel $^{\text {a }}$, E. Mascioli ${ }^{\text {a }}$, E. Zanelli ${ }^{\text {a,* }}$ \\ a Peptimmune Inc., 64 Sidney Street, Cambridge, MA-02139, USA \\ b Service de Neurologie, CIC-P 02-03, INSERM, Centre Hospitalier Universitaire rue Henri Le Guillou, 35033 Rennes, France \\ c CIMNA, CHU Hôtel-Dieu, quai Moncousu, 44093 Nantes, France
}

PI-2301 is an immunomodulator that could be an alternative therapy for MS. A placebo-controlled, multiple-ascending dose, double-blind study was performed in patients with secondary-progressive MS. Treatment was given subcutaneously once weekly for 8 weeks, followed by a 4-week openlabel treatment period with active drug. The most common adverse event was transient injection site reactions. Non-significant trend for increases in serum levels of IL-3, IL-13, and CCL22 over time were suggestive of a beneficial $\mathrm{T}_{\mathrm{H}} 2$ immune response in subjects dosed with PI-2301 at 3 and $10 \mathrm{mg}$. MRI data indicated a non-significant trend for a reduction of lesion numbers in subjects treated with 1 and $3 \mathrm{mg}$ PI-2301.

\section{Introduction}

Glatiramer acetate (Copaxone ${ }^{\circledR}$ ) is an amino acid copolymer, a mixture of peptides of various length synthesized using four amino acids, Y, E, A, and $\mathrm{K}$, in a defined ratio but in random order (Varkony et al., 2009; Teitelbaum et al., 1971). Treatment of relapsing remitting MS (RR-MS) with Copaxone requires once daily subcutaneous (SC) administration of a $20 \mathrm{mg}$ dose. Recent efforts using a higher molecular weight fraction of Copaxone, known as Protiramer, have hypothesized that the larger molecular weight peptide species are more immunoreactive than the lower ones, thus allowing for less frequent dosing, i.e., once weekly. However, results of two pilot studies in RR-MS patients have been inconclusive so far (De Stefano et al., 2009).

Copaxone's most common side effects are injection site reactions and transient, self-resolving, systemic post-injection reactions such as chest pain, flushing, dyspnea, palpitations, and anxiety (Ziemssen et al., 2001). However, Copaxone has not been associated with clinically

\footnotetext{
is The authors from Peptimmune Inc., a for-profit organization, are employees and Dr. Gilles Edan is a consultant for Peptimmune Inc. The employees of CIMNA were contracted for services.

* Corresponding author. Tel.: + 1617715 8042; fax: +1 6176618855 .

E-mail address: eric.zanelli@peptimmune.com (E. Zanelli).
}

significant immune suppression or other serious side effects (Boggild, 2009). Daily SC administration of Copaxone to patients with RR-MS has been shown to significantly decrease relapse rates, slow disability progression, and reduce the number of new gadolinium-enhancing CNS lesions (Dhib-Jalbut, 2003).

Although the mechanisms underlying amino acid copolymer efficacy in MS are not fully elucidated, down modulation of anti-self immune responses through binding to major histocompatibility complex (MHC) molecules is believed to be a central component (Fridkis-Hareli et al., 1994) as well as $T_{H} 1$ to $T_{H} 2$ immune deviation (Miller et al., 1998). Such mechanisms are fundamentally distinct from mechanisms of other RRMS therapeutic modalities, such as beta-interferon (e.g., Avonex®, Betaseron ${ }^{\circledR}$, Rebif ${ }^{\circledR}$ ) or alpha-4 integrin inhibitor (Tysabri ${ }^{\circledR}$ ) treatments which interfere with cellular migration (Dressel et al., 2007; Prat et al., 2005; Papeix and Lubetzki, 2009). Patients suffering from RR-MS are at need for a better immunomodulator that is safe and does not require daily injections. With secondary-progressive MS (SP-MS), the therapeutic options are limited as most existing therapies for MS are not efficacious in this subset of MS patients. The only compound approved for SP-MS is mitoxantrone, but it is not commonly used due to its toxicity (Jarius et al., 2003; Comi, 2009; Martinelli et al., 2009).

PI-2301 is a new immunomodulator in the class of amino acid copolymers. PI-2301 contains four naturally occurring amino acids Y, F, A, and $\mathrm{K}$. It is made of 52-mer peptides manufactured using solid-phase 
synthesis and acetylated at the NH2 terminus, in contrast to Copaxone made of non-acetylated peptides ranging from 20 to 200 amino acids and manufactured by solution-phase synthesis. The lack of short peptides, i.e., less than 52-mers, and the N-terminal acetylation significantly increase the protection of PI-2301 from peptidase degradation resulting in enhanced serum exposure and more efficient capture by antigenpresenting cells.

PI-2301 has been shown to bind antigenic peptide-presenting MHC Class II molecules with greater avidity than Copaxone (FridkisHareli et al., 2002). PI-2301 binds various MHC Class II molecules including HLA-DR2, encoded by HLA-DRA 0101 and HLA-DRB1 ${ }^{*} 1501$ which is the main predisposing allele for MS (Fridkis-Hareli et al., 2002; Gauthier et al., 1998). PI-2301's promiscuous binding to various HLA polymorphic variants makes it potentially clinically efficacious in a wide range of MS patients (Fridkis-Hareli et al., 2002).

PI-2301 has shown significantly better immunomodulatory effects in pre-clinical studies when compared to Copaxone (Illés et al., 2004; Stern et al., 2004). PI-2301 has also been shown to be safe in a single ascending dose study in human subjects; transient self-resolving injection site reaction was the most common adverse event (accepted manuscript in Journal of Clinical Pharmacology). In comparison to Copaxone, PI-2301 is designed to be administered weekly, rather than daily. Thus, weekly administration of PI-2301 will result in fewer injections for the patient and will probably enhance patient compliance.

Here we report the results of a Phase Ib multicenter study in subjects with SP-MS that was designed to determine primarily the safety of once weekly SC administrations of PI-2301 at 1, 3, 10, 30, and $60 \mathrm{mg}$ for 12 consecutive weeks. We also examined the effect of these weekly injections of PI-2301 on the immune function by looking at standard lymphocyte subsets through cytofluorometry, serum levels of mechanistically relevant soluble factors, and anti-compound antibody titers. Our intention was to identify potential biomarkers of efficacy and safety that could be used in future clinical trials involving a larger number of patients. Magnetic resonance imaging (MRI) and expanded disability status score (EDSS) were also monitored.

\section{Materials and methods}

\subsection{Study design}

This study was a placebo-controlled, multiple-ascending dose (MAD), double-blind study performed in subjects with SP-MS. The study was conducted in accordance with The Declaration of Helsinki adopted by the World Medical Assembly in June 1964, and all applicable national laws. The study was conducted on an out-patient basis for approximately 13 weeks, with all medication administered and assessments made at weekly clinical visits during a 12-week period. After signing an informed consent document and completing screening assessments (Visit 1 (initial screening visit)), eligible subjects received double-blind medication weekly (starting on Visit 2, (Dose 1)) for 8 weeks, followed by a 4 -week open-label treatment period for all subjects (starting Visit 10, (Dose 9)). During the double-blind period, subjects were randomized according to a 6:2 treatment ratio with either a fixed dose of PI-2301 $(1,3,10,30,60 \mathrm{mg}$ PI-2301 with a maximum concentration of $20 \mathrm{mg} / \mathrm{mL}$ in $42 \mathrm{mg} / \mathrm{mL}$ mannitol) or placebo (42 mg/ $\mathrm{mL}$ mannitol). All medications were administered subcutaneously (SC). Injection volume did not exceed $1 \mathrm{~mL}$, so for subjects receiving 30 or $60 \mathrm{mg}$ of PI-2301 two or three injection sites were used respectively.

Table 1 shows the demographics of each cohort (France $n=22$, Serbia $n=17$, and Hungary $n=11$ ). The first group of subjects entering the study were treated with the lowest dose of PI-2301 tested. Additional cohorts were treated with higher doses of PI-2301, with the increase in dosing following a step-wise fashion. The start of treatment for the next cohort, at the next higher dose, began after all subjects in the previous cohort had received at least 4 weekly doses of study drug, completed safety assessments, and with unanimous agreement by a dose escalation committee constituted of four physicians was obtained. Subjects randomized to placebo for the first 8 weeks of the study received treatment with PI-2301 at the corresponding dose of their respective cohorts during the last 4 weeks of the study (open-label period). A final assessment occurred at 13 weeks after the first dose (Visit 14 (1 week after Dose 12)) (Fig. 1).

Subjects were monitored for treatment emergent adverse events (TEAEs) that occurred within the $48 \mathrm{~h}$ after dosing (during the hospitalization period) or that were present prior to dosing and exacerbated within the $48 \mathrm{~h}$ after dosing. Basic urinalysis, hematology, and blood chemistry analysis were performed on each subject during the course of this study to assess the general health of all subjects. Each injection site was scored (scale of 0-4) for each of the following characteristics: erythema, induration, pruritus, nodules and/or cysts, ecchymosis, duration, pain, or other local signs or symptoms. All ISRs were recorded as AEs using standardized criteria and pre-specified descriptive terms as noted in the protocol. A cumulative score was generated for each subject for each visit with the highest cumulative score reported for that visit. The mean value \pm SEM was calculated for each dosing cohort. For subjects that had multiple injection sites or had injection site reactions (ISRs) from the previous dosing, these values were also added in the range of cumulative scores 0 (lowest) and 32 (highest for single injection site in 1, 3, and $10 \mathrm{mg}$ cohorts), 64 (highest for two injection sites in the $30 \mathrm{mg}$ cohort), or 96 (highest for three injection sites in the $60 \mathrm{mg}$ cohort.)

Table 1

Summary of demographic characteristics at baseline $(N=50)$.

\begin{tabular}{|c|c|c|c|c|c|c|c|c|}
\hline \multirow{2}{*}{$\begin{array}{l}\text { Parameter } \\
\text { (unit) }\end{array}$} & \multirow{2}{*}{$\begin{array}{l}\text { Statistics/ } \\
\text { category }\end{array}$} & \multicolumn{5}{|l|}{ PI-2301 } & \multirow{2}{*}{$\begin{array}{l}\text { Placebo } \\
(N=14)\end{array}$} & \multirow{2}{*}{$\begin{array}{l}\text { Overall } \\
(N=50)\end{array}$} \\
\hline & & $\begin{array}{l}1 \mathrm{mg} \\
(N=6)\end{array}$ & $\begin{array}{l}3 \mathrm{mg} \\
(N=7)\end{array}$ & $\begin{array}{l}10 \mathrm{mg} \\
(N=9)\end{array}$ & $\begin{array}{l}30 \mathrm{mg} \\
(N=6)\end{array}$ & $\begin{array}{l}60 \mathrm{mg} \\
(N=8)\end{array}$ & & \\
\hline \multirow[t]{2}{*}{ Age (years) } & Mean & 48.2 & 48.4 & 45.6 & 44.0 & 48.3 & 44.4 & 46.2 \\
\hline & SD & 8.5 & 7.1 & 7.2 & 6.5 & 8.2 & 8.8 & 7.8 \\
\hline \multirow[t]{2}{*}{ Sex } & Male & 2 & 3 & 5 & 2 & 2 & 6 & 20 \\
\hline & Female & 4 & 4 & 4 & 4 & 6 & 8 & 30 \\
\hline \multirow[t]{3}{*}{ Country } & France & 6 & 3 & 3 & 0 & 3 & 7 & 22 \\
\hline & Serbia & 0 & 1 & 5 & 6 & 0 & 5 & 17 \\
\hline & Hungary & 0 & 3 & 1 & 0 & 5 & 2 & 11 \\
\hline \multirow[t]{3}{*}{ Race } & Caucasian & 4 & 6 & 9 & 6 & 8 & 13 & 46 \\
\hline & Black & 1 & 0 & 0 & 0 & 0 & 0 & 1 \\
\hline & Other & 1 & 1 & 0 & 0 & 0 & 1 & 3 \\
\hline \multirow[t]{2}{*}{ Weight (kg) } & Mean & $70.9^{*}$ & 63.7 & 76.9 & 60.4 & 70.0 & 72.9 & 70.1 \\
\hline & SD & 8.1 & 13.7 & 15.0 & 8.6 & 13.0 & 12.3 & 13.2 \\
\hline \multirow[t]{2}{*}{ Height $(\mathrm{cm})$} & Mean & 168.8 & 167.9 & 172.4 & 173.5 & 170.3 & 172.4 & 171.1 \\
\hline & $\mathrm{SD}$ & 8.0 & 13.2 & 10.2 & 7.3 & 7.7 & 9.1 & 9.2 \\
\hline
\end{tabular}

\footnotetext{
* $N=3$, data not available for three subjects.
} 


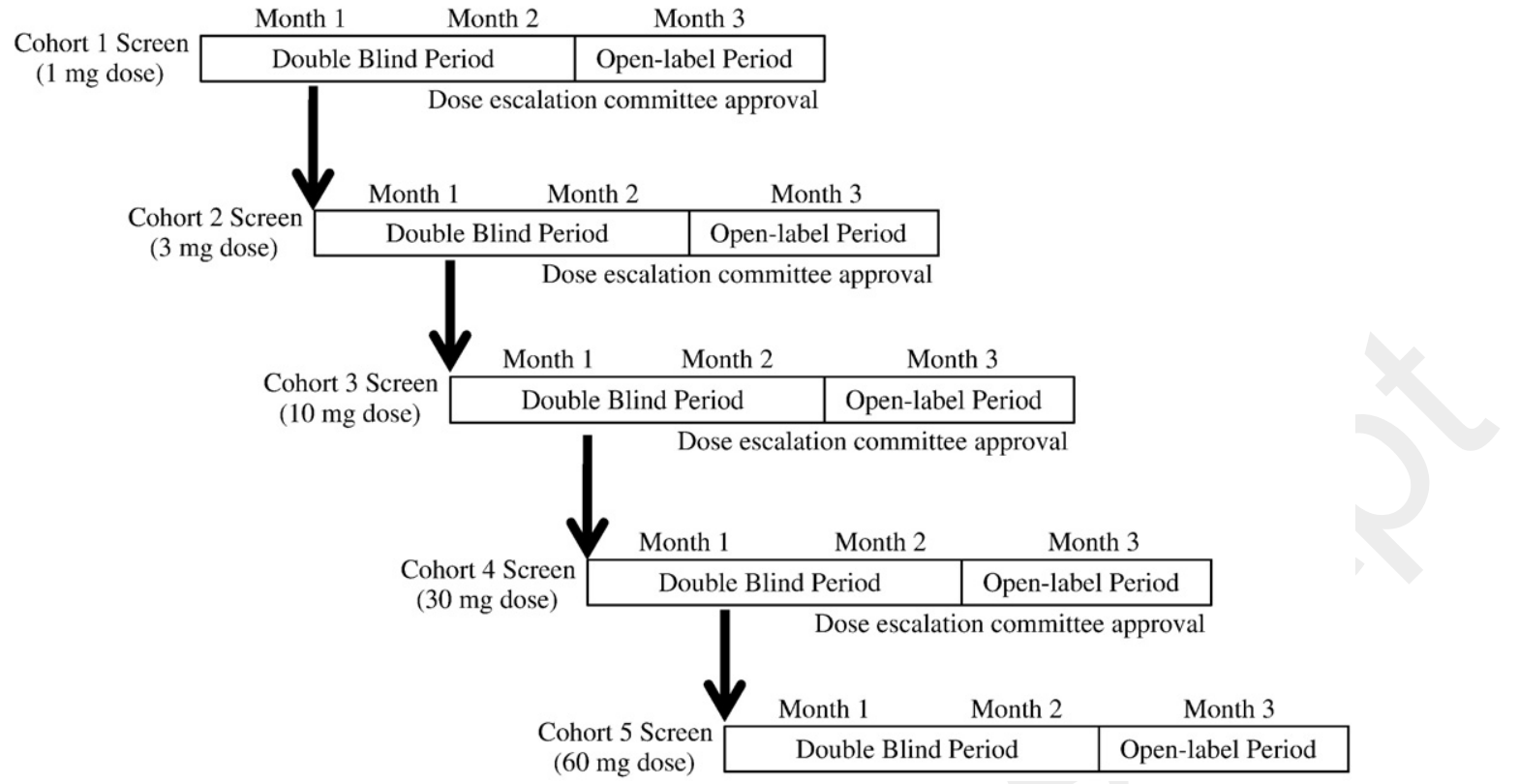

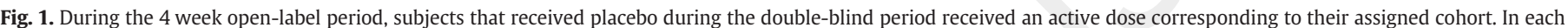

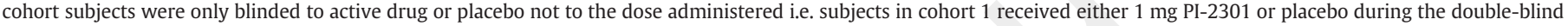

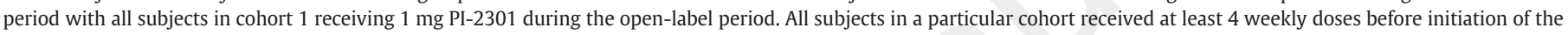
subsequent cohort.

\subsection{Subject inclusion/exclusion criteria}

Subjects were male or female (non-pregnant) patients that were currently diagnosed with SP-MS with a duration of diagnosis of at least 1 year and less than 10 years prior to the baseline examination. Subjects were between the ages of 18 and 60. Subjects had to have evidence of MS obtained by MRI (T1 weighted imaging with gadolinium contrast) using a 1.5 Tesla $(\mathrm{T})$ magnet within 1 year of the baseline examination with $\leq 10$ active gadolinium-enhancing lesions. Subjects also had to have a score on the expanded disability status scale (EDSS) of $\geq 3$ and $<7$.

Subjects were excluded from this trial if they had any medical condition that would jeopardize the safety of the subject or impact the validity of the study results, other than SP-MS, or had any relapse of MS within 3 months prior to the beginning of the trial. Subjects that were immunosuppressed in any way, had a history of hepatitis B or C, had any prior history of Copaxone ${ }^{\circledR}$, Cellcept, or Campath use, had glucocorticoid therapy 3 months prior to the beginning of the trial, or any other treatment that may lead to immunosuppression 6 months prior to the beginning of the trial were also excluded.

\subsection{Cytometric analysis of lymphocytes and pharmacodynamic serum markers in response to PI-2301}

Whole blood samples were collected in blood collection tubes containing EDTA (for lymphocyte cytometric analysis) or in collection tubes without additives for the collection of serum (for pharmacodynamic serum marker analysis) on Visit 2 (Dose 1 (pre-dose and 4 h postdose)), Visit 6 (Dose 5 (pre-dose and 4 h post-dose)), Visit 10 (Dose 9 (pre-dose and $4 \mathrm{~h}$ post-dose)), and Visit 14 (1 week after Dose 12 (blood was collected at one time point since no compound was administered)).

Lymphocyte samples were collected and shipped to CIMNA (Nantes, France) or Szent Laszlo Hospital Asboth Oszkar FACS Laboratory (Budapest, Hungary) at room temperature on the day of collection for analysis within $24 \mathrm{~h}$. Samples were tested for percentages and absolute counts of the following lymphocyte populations: CD3 + T cells, CD3+/ CD4+ helper T cells, CD3+/CD8+ cytotoxic T cells, CD3+/CD4+/CD8+ T cells, CD19+ B cells, and CD3-/16 and/or CD56+ NK cells. Analysis was performed using the MultiTEST CD3 FITC/CD8 PE/CD45 PerCP/CD4 APC Kit, MultiTEST CD3 FITC/CD16 + CD56 PE/CD45 PerCP/CD19 APC Kit, and the TruCOUNT tubes (Becton Dickinson, Franklin Lakes, NJ, USA; cat\#340499, cat\#340500, and cat\#340492, respectively) following the manufacturers protocols. All samples were within normal physiologic range indicating cell viability.

Whole blood was also collected and remained at room temperature for $40 \mathrm{~min}$ before centrifugation $\left(3500 \times \mathrm{g}\right.$ for $10 \mathrm{~min}$ at $\left.4^{\circ} \mathrm{C}\right)$. Serum samples were stored on site at $-20^{\circ} \mathrm{C}$ and shipped by cohort batch after Visit 6 and Visit 14 at $-80^{\circ} \mathrm{C}$. Serum samples were shipped to Rules Based Medicine (Austin, TX, USA) for the analysis of pharmacodynamic serum markers. At Rules Based Medicine, each sample was thawed at room temperature, vortexed, centrifuged at $13,000 \times \mathrm{g}$ for $5 \mathrm{~min}$ for clarification, and $40 \mu \mathrm{L}$ was removed for Human MAP antigen (version 1.6) analysis. The pharmacodynamic markers tested were the following: interferongamma (IFN- $\gamma$ ), tumor necrosis factor-alpha (TNF- $\alpha$ ), tumor necrosis factor-beta (TNF- $\beta$ ), monocyte chemoattractant protein-1 (MCP-1), macrophage inflammatory protein-1 alpha (MIP-1 $\alpha$ ), macrophage inflammatory protein-1 beta (MIP-1 $\beta$ ), macrophage-derived chemokine (MDC), brain-derived nerve growth factor (BDNF), Granulocyte colonystimulating factor (G-CSF), Granulocyte-macrophage colony-stimulating

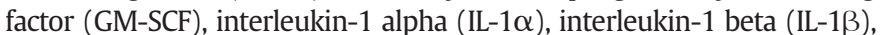
interleukin-2 (IL-2), interleukin-3 (IL-3), interleukin-4 (IL-4), interleukin5 (IL-5), interleukin-6 (IL-6), interleukin-7 (IL-7), interleukin-8 (IL-8), interleukin-10 (IL-10), interleukin-12p40 (IL-12p40), interleukin-12p70 (IL-12p70), interleukin-13 (IL-13), interleukin-15 (IL-15), interleukin-16 (IL-16), and interleukin-18 (IL-18).

Tryptase activity was examined from serum samples by the Center Eugène Marquis (Rennes, France) collected pre-dose, 10 min postdosing, and $2 \mathrm{~h}$ post-dosing for Visits $2-13$ (Doses 1 to 12 ).

\subsection{Anti-PI-2301 antibody titers and pharmacokinetics of PI-2301}

Anti-PI-2301 antibody titers (IgG1-4) and total IgE were assessed on Visit 2 (Dose 1), Visit 6 (Dose 5), Visit 10 (Dose 9), and Visit 14 (1 week after Dose 12). To measure anti-PI-2301 IgG titers, PI-2301 at a concentration of $0.4 \mu \mathrm{g} /$ well was immobilized onto a 96 -well microtiter plate overnight at $4{ }^{\circ} \mathrm{C}$, then washed with a PBS $0.05 \%$ Tween 20 wash 
solution and blocked (10\% FBS/PBS) for $2 \mathrm{~h}$. Following a wash step, serially diluted serum samples were added to the wells and incubated for $2 \mathrm{~h}$, allowing anti-PI-2301 antibodies to bind to the immobilized PI-2301. Unbound material was then washed away and a mouse antihuman $\operatorname{IgG1}, 2$, 3, or 4 antibody conjugated to HRP (Southern Biotech, Birmingham, AL, USA) was added to the wells for $1 \mathrm{~h}$. Unbound detection antibody was removed by washing and a substrate (TMB/ $\mathrm{H}_{2} \mathrm{O}_{2}$ from VWR; West Chester, PA, USA) was added to the wells and incubated for 15 min after which stop solution ( $2 \mathrm{~N} \mathrm{H}_{2} \mathrm{SO}_{4}$ from VWR; West Chester, PA, USA) was added. The optical density was measured on a Tecan Shell microplate reader at $450 \mathrm{~nm}$ and the intensity of the color measured was proportional to the amount of anti-PI-2301 antibody bound by the immobilized PI-2301. Total IgE was measured in serum samples sent to Rules Based Medicine (RBM; Austin, TX, USA).

The pharmacokinetic assay for PI-2301 is a qualified direct competition ELISA. This method was transferred to and qualified by Avogadro (Fontenilles, France) and is acceptable to give relative quantitative levels of PI-2301 concentrations in human serum in a linear range of $69-527 \mathrm{ng} / \mathrm{mL}$ (with a limit of detection of $27 \mathrm{ng} / \mathrm{mL}$ ). Intra-assay precision using the \% coefficient of variation (CV) was 2.9 to 13.2 and the inter-assay precision was 5.9 to 13.2. This method can detect $\geq 30$-mer peptide fragments of PI-2301 which are biologically active (data not shown) and non-specific binding (as calculated by \% bound/maximal binding) was $6.6 \%$. The assay passed all stability controls for samples kept at $-80{ }^{\circ} \mathrm{C}$ for up to 4 months.

Briefly, PI-2301 is immobilized on a 96-well microtainer plate overnight at $4{ }^{\circ} \mathrm{C}$, then blocked for $2 \mathrm{~h}$, and washed. Human serum (a pool of 10 male donors from Bioreclamation Westbury, NY, USA) containing known or unknown concentrations of PI-2301 are added to the washed plates along with Protein A purified biotinylated anti-PI2301 antibodies (made in-house from rabbit polyclonal antiserum produced by Maine Biotechnology Services Portland, ME, USA) and incubated for $2 \mathrm{~h}$ on a plate shaker. Unbound material is washed away and diluted streptavidin-HRP conjugate is added to the wells and incubated, yielding a blue color that turns yellow when stop solution is added. The optical density is measured at $450 \mathrm{~nm}$, and a standard curve is generated. The intensity of the color measured is proportional to the amount of biotinylated anti-PI-2301 antibody bound by the immobilized PI-2301 (method in manuscript accepted by The Journal of Clinical Pharmacology).

A pharmacokinetic analysis on individual serum levels (by subject) was done with Kinetica ${ }^{\circledR}$ software version 4.1.1 (Innaphase, now Thermo Scientific, Waltham, MA, USA) in order to determine the main pharmacokinetic parameters by subject.

\subsection{MRI and EDSS}

MRI examinations and completion of the EDSS were obtained during the initial screening visit (Visit 1), Visit 10 (Dose 9), and Visit 14 (1 week after Dose 12). The MRI included T1 scans with gadolinium. The scans were read for both gadolinium-enhancing lesion count and lesion volume.

\subsection{Statistical and analytical plan}

Safety and activity data were analyzed by The Biostatistics Unit of BIOTRIAL using SAS® software 8.2 release (SAS Institute Inc., Cary, NC, USA). The pharmacokinetic analysis was performed by Avogadro SA (Fontenilles, France). For safety and activity parameters, descriptive statistics were supplied. Data were organized by dose group with all the placebo-treated subjects pooled in a single group. In-depth data analysis for soluble serum pharmacodynamic marker release was performed on markers in which $>99 \%$ of samples were in the detectable range of the assay. Graphical and statistical analysis of the MRI, antibody titer, soluble serum pharmacodynamic marker release, cytometric analysis, and injection site reactions were analyzed using Graph Pad Prism ${ }^{\circledR}$

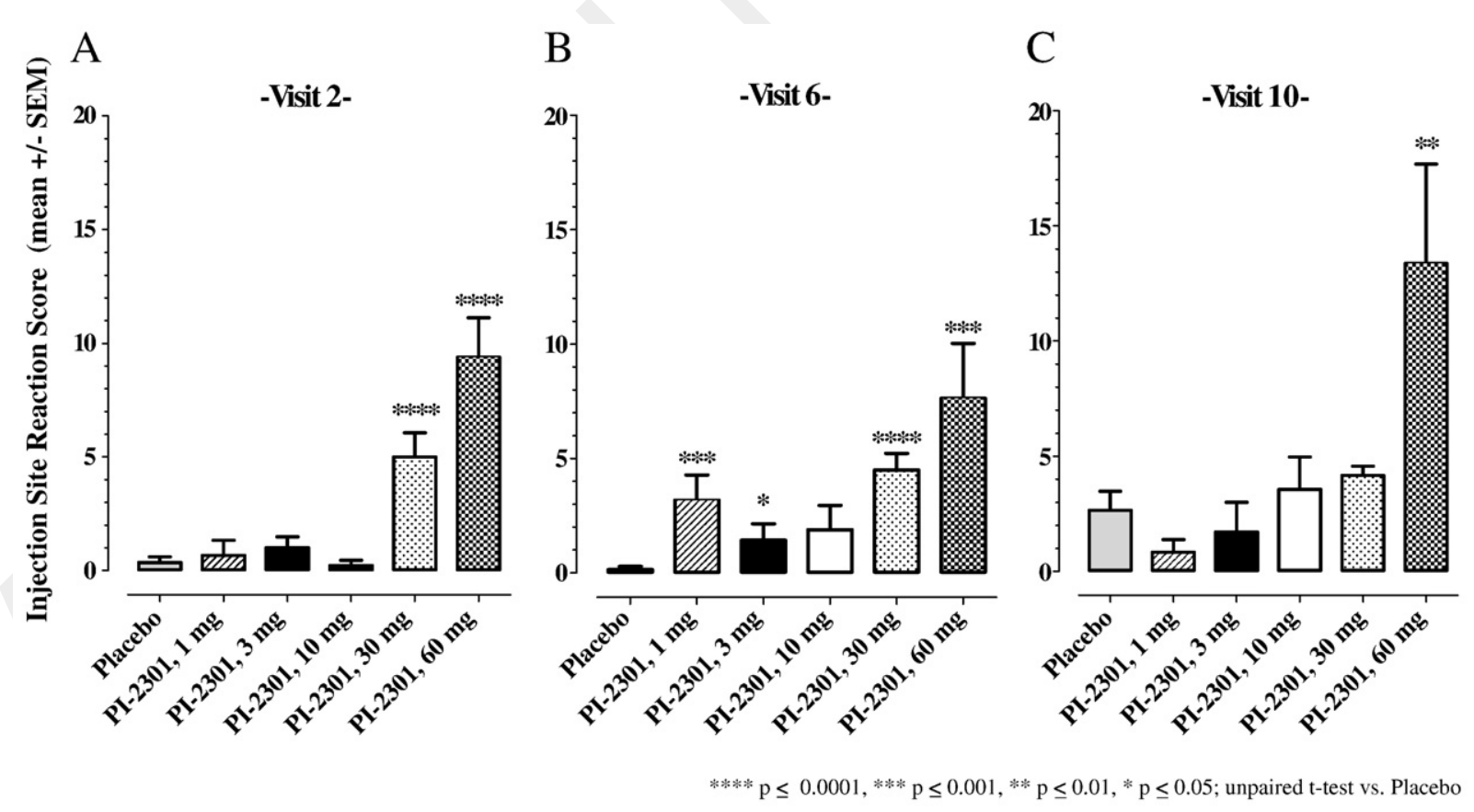

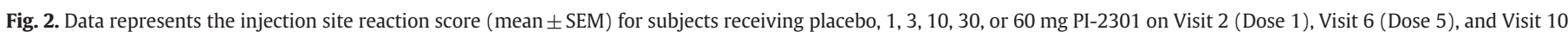

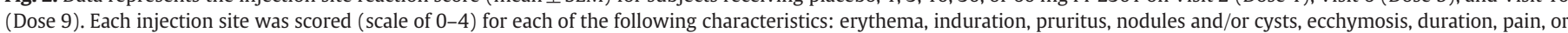

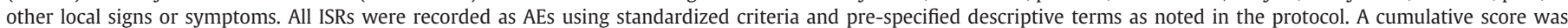

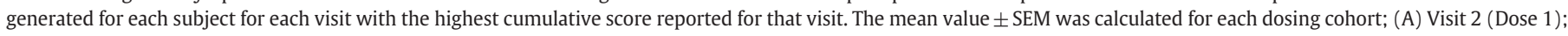

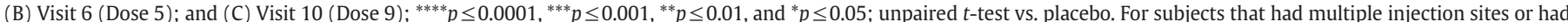

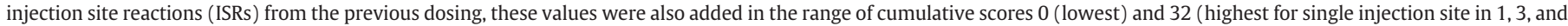

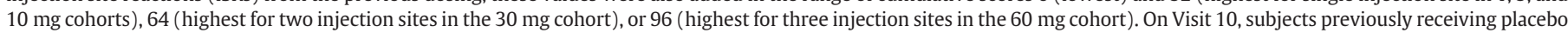
(Visits 2-9) received their first dose of active drug (open-label) which explains the increase in ISR score. 

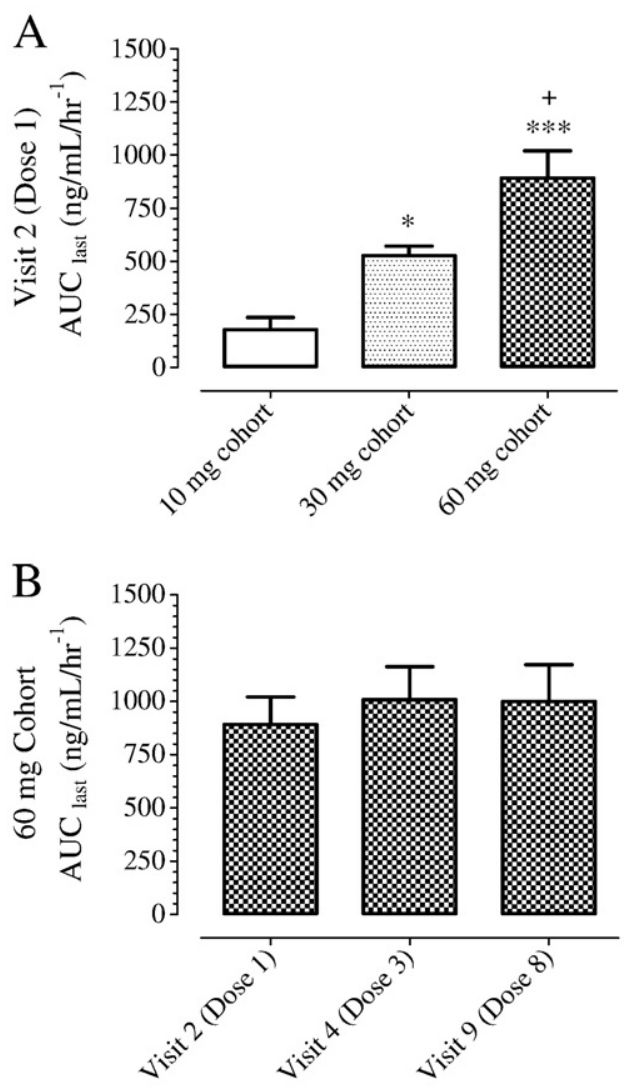

Fig. 3. (A) Area under the curve $\left(A U C_{\text {last }} \mathrm{ng} / \mathrm{mL} /\right.$ hour $^{-1}$ ) progressively increased as the SC dose of PI-2301 increased when comparing 10, 30, and $60 \mathrm{mg}$ cohorts on Visit 2 (Dose 1). ${ }^{*} p \leq 0.05,{ }^{* * *} p \leq 0.001$ vs. $10 \mathrm{mg}$ cohort; $+p \leq 0.05 \mathrm{vs}$. $30 \mathrm{mg}$ cohort (one-way analysis of variance using a Bonferroni's multiple comparison test). (B) There was not a significant increase in PI-2301 accumulation in the serum during the time course of the study in subjects that had detectable levels of PI-2301 in the serum and received multiple treatments. Comparison of the $60 \mathrm{mg}$ cohort on Visit 2 (Dose 1), Visit 4 (Dose 3), and Visit 9 (Dose 8 ) showed no accumulation by $\mathrm{AUC}_{\text {last }}\left(\mathrm{ng} / \mathrm{mL} / \mathrm{hour}^{-1}\right.$ ) (one-way analysis of variance using a Bonferroni's multiple comparison test). Data is represented as mean \pm SEM. At doses below $10 \mathrm{mg}$, there was no detectable PI-2301 serum level.

Version 5.0. Data was plotted as mean \pm SEM with unpaired $t$-test to compare data between cohorts and a paired $t$-test to compare data within cohorts at different time points. Pharmacokinetic data was analyzed using a one-way analysis of variance utilizing the Bonferroni's multiple comparison test. Since variance among groups differs significantly, soluble serum pharmacodynamic marker release was also analyzed using a non-parametric one-way analysis of variance utilizing the Kruskal-Wallis test with a Dunn's multiple comparison test specifically comparing each dosing cohort to the placebo cohort. Nonparametric correlations of linear regression for soluble serum pharmacodynamic marker release were calculated.

\section{Results}

Demographic data of the subject population can be found in Table 1 . Out of a total of 488 potential subject-weeks, 482 were completed because 3 subjects, one from the $30 \mathrm{mg}$ group and 2 from the $60 \mathrm{mg}$ group, dropped out due to adverse events (AEs). The most frequent treatment emergent adverse events (TEAEs) for all subjects receiving PI-2301 (12 weeks) or placebo (8-week double blind) were mild to moderate transient injection site reactions (ISRs), which were selflimited and resolved without therapy. Generally, the incidence and severity of the ISRs was less in subjects receiving placebo. The occurrences of ISR increased as the dose administered increased. On Visit 2 (Dose 1), subjects in the 30 and $60 \mathrm{mg}$ PI-2301 cohorts had significant ISRs as compared to placebo-treated subjects $(p \leq 0.0001$; unpaired $t$-test) (Fig. 2A). Subjects in the 1, 3, and $10 \mathrm{mg}$ PI-2301 cohorts showed no difference when compared to placebo. However, on Visit 6 (Dose 5), subjects in the 1, 3, 30, and $60 \mathrm{mg}$ PI-2301 cohorts had significant ISRs when compared to placebo $(p=0.0006, p=0.0268$, $p \leq 0.0001$, and $p=0.0005$; unpaired $t$-test, respectively) (Fig. 2B). On Visit 10 (Dose 9), only subjects receiving $60 \mathrm{mg}$ PI-2301 had significant ISRs when compared to subjects receiving placebo $(p=0.0048$; unpaired $t$-test) (Fig. 2C). On Visit 10 , subjects previously receiving placebo (Visits 2-9) received their first dose of active drug (open-label) which explains the increase in ISR score. It should be noted again that all ISRs were mild to moderate. In general, it appears that ISRs did not increase in severity over the course of the trial for any of the individual cohorts.

One severe adverse event (SAE) was reported, a case of somnolence, with asthenia and blurred vision in a subject after two injections of PI-2301 at $30 \mathrm{mg}$ (patient had been in the placebo group for the first 8 weeks, and received $30 \mathrm{mg}$ during the open-label period), for which the subject was hospitalized. No etiology was found for this SAE, and therefore the relation to PI-2301 could not be definitively ascertained. The subject made a full recovery.

Urinalysis, hematology, and blood chemistry showed no clinically relevant changes in any parameter examined for any subject (data not shown). Tryptase activity, which has been used as a marker of mastcell activation (Bargagli et al., 2009; Saito et al., 2009), anti-PI-2301

Table 2

Lymphocyte cytometric analysis (mean \pm SEM).

\begin{tabular}{|c|c|c|c|c|c|c|c|}
\hline & & $\begin{array}{l}\text { \% Lymph T } \\
\text { CD3+ }\end{array}$ & $\begin{array}{l}\text { \% Lymph T } \\
\text { CD3+/CD4+ }\end{array}$ & $\begin{array}{l}\text { \% Lymph T } \\
\text { CD3+/CD8+ }\end{array}$ & $\begin{array}{l}\text { \% Lymph T } \\
\text { CD3+/CD4+/CD8+ }\end{array}$ & $\begin{array}{l}\text { \% Lymph B } \\
\text { CD19+ }\end{array}$ & $\begin{array}{l}\text { \% Lymph NK } \\
\text { CD3-/16 and/or } 56+\end{array}$ \\
\hline \multirow[t]{3}{*}{$1 \mathrm{mg}$} & Pre Visit 2 & $71.54 \pm 3.43$ & $48.07 \pm 3.55$ & $21.85 \pm 3.51$ & $1.27 \pm 0.32$ & $13.56 \pm 1.39$ & $14.09 \pm 4.11$ \\
\hline & Post Visit 2 & $71.87 \pm 2.59$ & $48.72 \pm 2.79$ & $21.71 \pm 3.50$ & $1.33 \pm 0.35$ & $14.24 \pm 1.87$ & $13.36 \pm 3.54$ \\
\hline & Visit 14 & $72.27 \pm 2.29$ & $48.77 \pm 3.13$ & $21.80 \pm 3.44$ & $1.38 \pm 0.36$ & $13.97 \pm 1.72$ & $12.87 \pm 2.48$ \\
\hline \multirow[t]{3}{*}{$3 \mathrm{mg}$} & Pre Visit 2 & $76.17 \pm 4.09$ & $47.70 \pm 2.51$ & $26.67 \pm 3.51$ & $1.14 \pm 0.23$ & $14.76 \pm 3.85$ & $8.80 \pm 1.42$ \\
\hline & Post Visit 2 & $76.67 \pm 3.44$ & $48.81 \pm 2.74$ & $26.51 \pm 3.42$ & $0.99 \pm 0.16$ & $15.02 \pm 3.39$ & $7.60 \pm 0.81$ \\
\hline & Visit 14 & $77.20 \pm 3.16$ & $48.79 \pm 1.84$ & $26.57 \pm 2.77$ & $1.26 \pm 0.16$ & $13.04 \pm 3.12$ & $8.49 \pm 1.33$ \\
\hline \multirow[t]{3}{*}{$10 \mathrm{mg}$} & Pre Visit 2 & $72.45 \pm 4.08$ & $46.36 \pm 3.60$ & $26.82 \pm 3.64$ & $1.83 \pm 0.52$ & $15.43 \pm 2.41$ & $11.22 \pm 2.96$ \\
\hline & Post Visit 2 & $73.35 \pm 3.25$ & $47.14 \pm 3.29$ & $27.11 \pm 3.93$ & $1.81 \pm 0.61$ & $15.55 \pm 2.50$ & $10.23 \pm 1.90$ \\
\hline & Visit 14 & $72.26 \pm 3.71$ & $45.58 \pm 3.05$ & $27.33 \pm 3.76$ & $1.99 \pm 0.52$ & $15.35 \pm 2.20$ & $12.18 \pm 3.03$ \\
\hline \multirow[t]{3}{*}{$30 \mathrm{mg}$} & Pre Visit 2 & $74.59 \pm 3.68$ & $49.40 \pm 3.24$ & $24.06 \pm 2.70$ & $0.97 \pm 0.22$ & $11.48 \pm 1.35$ & $11.98 \pm 3.05$ \\
\hline & Post Visit 2 & $75.52 \pm 3.73$ & $49.53 \pm 3.21$ & $24.96 \pm 2.82$ & $1.11 \pm 0.31$ & $11.25 \pm 0.99$ & $12.38 \pm 3.12$ \\
\hline & Visit 14 & $75.58 \pm 3.13$ & $50.59 \pm 3.99$ & $23.65 \pm 3.32$ & $1.08 \pm 0.20$ & $11.19 \pm 1.06$ & $12.10 \pm 2.61$ \\
\hline \multirow[t]{3}{*}{$60 \mathrm{mg}$} & Pre Visit 2 & $76.90 \pm 2.55$ & $50.04 \pm 4.07$ & $25.70 \pm 3.13$ & $1.30 \pm 0.31$ & $11.52 \pm 1.04$ & $10.75 \pm 1.81$ \\
\hline & Post Visit 2 & $76.49 \pm 3.03$ & $52.90 \pm 3.73$ & $22.68 \pm 2.46$ & $1.08 \pm 0.26$ & $13.77 \pm 2.71$ & $7.93 \pm 1.08$ \\
\hline & Visit 14 & $76.98 \pm 2.31$ & $50.57 \pm 3.28$ & $25.27 \pm 3.04$ & $1.32 \pm 0.22$ & $11.65 \pm 1.27$ & $10.66 \pm 1.43$ \\
\hline \multirow[t]{3}{*}{ Placebo } & Pre Visit 2 & $74.84 \pm 1.95$ & $50.36 \pm 1.68$ & $23.35 \pm 1.89$ & $0.92 \pm 0.13$ & $13.45 \pm 1.35$ & $10.73 \pm 1.32$ \\
\hline & Post Visit 2 & $75.40 \pm 1.93$ & $50.89 \pm 1.73$ & $23.46 \pm 1.93$ & $0.96 \pm 0.15$ & $13.37 \pm 1.42$ & $10.40 \pm 1.29$ \\
\hline & Visit 14 & $74.27 \pm 1.78$ & $49.81 \pm 1.87$ & $22.96 \pm 1.90$ & $1.04 \pm 0.17$ & $13.56 \pm 1.23$ & $11.82 \pm 1.37$ \\
\hline
\end{tabular}


antibody titers for $\operatorname{IgG} 1, \operatorname{IgG} 2, \operatorname{IgG} 4$, and total $\operatorname{IgE}$ showed no differences between treatments and did not increase over the time course of the study (data not shown). Three subjects, one subject in the $3 \mathrm{mg}$ cohort and two in the $10 \mathrm{mg}$ cohort, appeared to generate a limited anti-PI-2301 IgG3 antibody response. At the 1/400 dilution, serum from the subject in the $3 \mathrm{mg}$ cohort showed absorbances of $0.012,0.015,0.602$, and 0.437 on Visits $2,6,10$, and 14 respectively by ELISA on a scale from 0 to 4 . Values for the two subjects in the $10 \mathrm{mg}$ cohort at the same time points were $0.013,0.009,0.076,0.124$ and 0 , $0,0,0.132$, respectively.

Pharmacokinetic analysis showed the presence of PI-2301 in the serum in similar kinetics observed in our single ascending dose study (manuscript accepted in Journal of Clinical Pharmacology). At doses below $10 \mathrm{mg}$, there was no detectable PI-2301 serum level. $\mathrm{C}_{\text {max }}$ (mean \pm SEM) progressively increased as the SC dose of PI-2301 increased when comparing 10, 30, and $60 \mathrm{mg}$ cohorts on Visit 2 (Dose 1) (73.62 \pm $10.93 \mathrm{ng} / \mathrm{mL}, 184.97 \pm 14.73 \mathrm{ng} / \mathrm{mL}$, and $288.96 \pm 40.20 \mathrm{ng} / \mathrm{mL}$, respectively). The same was true when comparing the area under the curve $\left(\mathrm{AUC}_{\text {last }}\right)($ mean $\pm \mathrm{SEM})(177.82 \pm 57.94 \mathrm{ng} / \mathrm{mL} \mathrm{h}, 525.96 \pm 45.40 \mathrm{ng} /$ $\mathrm{mL} \mathrm{h}, 891.37 \pm 128.46 \mathrm{ng} / \mathrm{mL}$, respectively) (Fig. 3A). There was not a significant increase in PI-2301 accumulation in the serum during the time course of the study in subjects that had detectable levels of PI-2301 in the serum and received multiple treatments. Comparison of the $60 \mathrm{mg}$ cohort on Visit 2 (Dose 1), Visit 4 (Dose 3), and Visit 9 (Dose 8) showed no accumulation by $\mathrm{C}_{\max }($ mean $\pm \mathrm{SEM})(288.96 \pm 40.20 \mathrm{ng} / \mathrm{mL}, 313.79 \pm$
$47.68 \mathrm{ng} / \mathrm{mL}$, and $320.52 \pm 49.09 \mathrm{ng} / \mathrm{mL}$, respectively) or $\mathrm{AUC}_{\text {last }}$ (mean \pm SEM) $(891.37 \pm 128.46 \mathrm{ng} / \mathrm{mL} h, 1008.17 \pm 154.95 \mathrm{ng} / \mathrm{mL}$ h, $999.38 \pm$ $161.07 \mathrm{ng} / \mathrm{mL}$ h, respectively) (Fig. 3B).

Cytometric analysis was performed on PBMCs (Table 2) for several different lymphocyte populations (CD3+ T cells, CD3+/CD4+ helper $\mathrm{T}$ cells. $\mathrm{CD} 3+/ \mathrm{CD} 8+$ cytotoxic $\mathrm{T}$ cells, $\mathrm{CD} 3+/ \mathrm{CD} 4+/ \mathrm{CD} 8+\mathrm{T}$ cells, CD19+ B cells, and CD3-/16 and/or CD56+ NK cells). All samples were within normal physiologic range indicating cell viability. However, there were no significant differences observed between treatment groups for any populations evaluated.

\subsection{Pharmacodynamic markers of PI-2301}

Next we examined whether any pharmacodynamic markers of PI-2301 administration were evident during the course of the study. Since PI-2301 is an immunomodulator, serum samples were analyzed for serum cytokines and chemokines at time points and visits noted. The following 26 serum cytokines and chemokines were analyzed: IFN- $\gamma$, TNF- $\alpha$, TNF- $\beta$, MCP-1, MIP- $1 \alpha$, MIP- $1 \beta$, MDC, BDNF, G-CSF, GM-SCF, IL-1 $\alpha$, IL-1 $\beta$, IL-2, IL-3, IL-4, IL-5, IL-6, IL-7, IL-8, IL-10, IL-12p40, IL-12p70, IL-13, IL-15, IL-16, and IL-18. Of the 26 serum cytokines and chemokines tested, 17 (IFN- $\gamma$, TNF- $\alpha$, TNF- $\beta$, MIP-1 $\beta$, BDNF, G-CSF, GMSCF, IL-1 $\alpha$, IL-1 $\beta$, IL-2, IL-4, IL-5, IL-6, IL-10, IL-12p40, IL-12p70, and IL-15) had values that were not within the detectable range of the assay for several subject samples and therefore we were unable to statistically
A

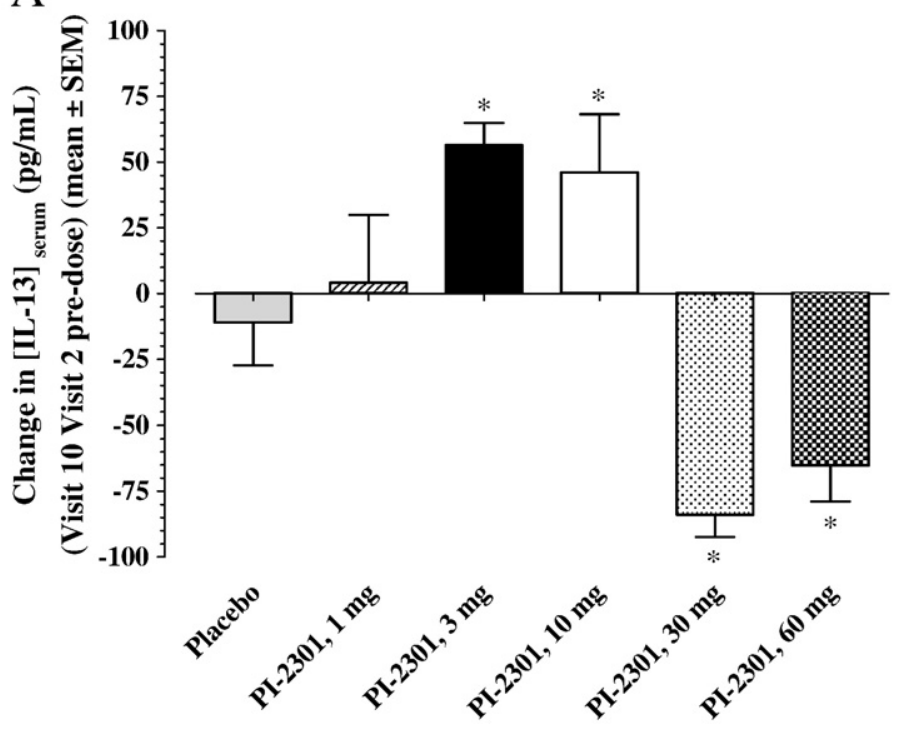

$*$ p $\leq 0.05$ vs. Placebo; unpaired t-test
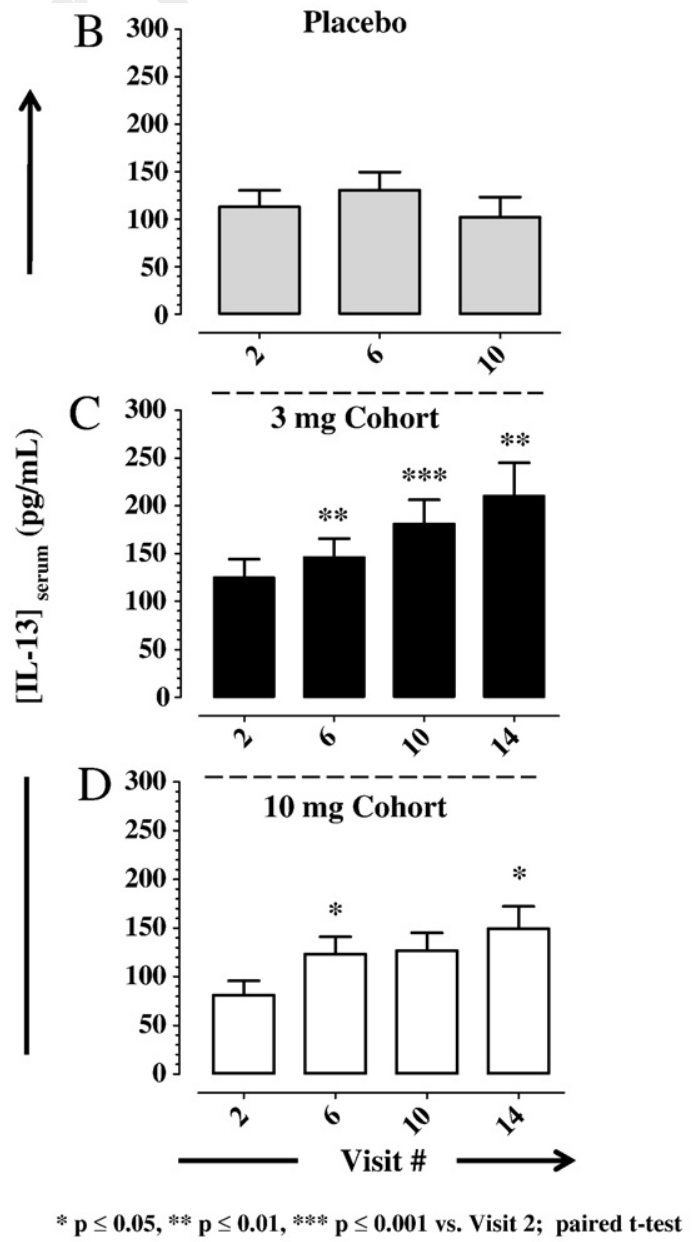

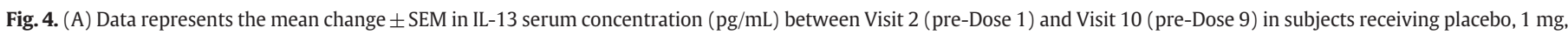

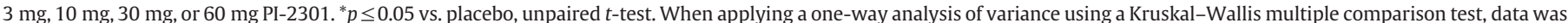

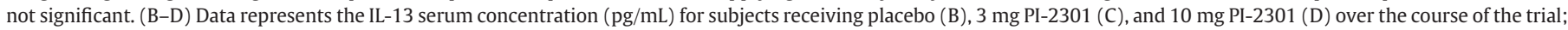

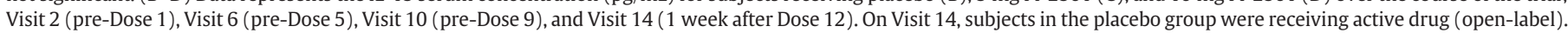
${ }^{*} p \leq 0.05,{ }^{* *} p \leq 0.01,{ }^{* * *} p \leq 0.001$ vs. Visit 2 (pre-Dose 1 ), paired $t$-test. 
analyze these markers. A descriptive analysis of cytokines and chemokines which are implicated in inflammation such as IFN- $\gamma$, TNF$\alpha$, IL-12p40, and IL-12p70 showed no clear trends in relation to PI-2301 administration. Even though IL-10 was not fully analyzed due to insufficient samples for each cohort, an apparent trend was observed showing an increase over time in the 3 and $10 \mathrm{mg}$ cohorts (data not shown). Since some samples were not within the range of detection, it is difficult to draw conclusions from this data. No other clear trends were observed in these cytokines or chemokines. Nine cytokines and chemokines (MCP-1, MIP-1 $\alpha$, MDC, IL-3, IL-7, IL-8, IL-13, IL-16, and IL18) were further analyzed as pharmacodynamic markers.

IL-3, IL-13, and MDC (CCL22) were of particular interest when comparing serum levels at Visit 2 (pre-Dose 1) to Visit 10 (pre-Dose 9). We specifically evaluated Visit 10 (pre-Dose 9) because the placebo subjects were on active drug between Visit 10 (Dose 9) and Visit 14 (1 week after Dose 12). Fig. 4A shows that there was a significant increase in IL-13 on Visit 10 (pre-Dose 9) between subjects receiving placebo and the $3 \mathrm{mg}$ ( $p=0.0116$; unpaired $t$-test) and $10 \mathrm{mg}$ cohorts ( $p=0.0471$; unpaired $t$-test). However, when applying a one-way analysis of variance using a Kruskal-Wallis multiple comparison test, the significance was lost. No significant increase in IL-13 serum concentration was observed in subjects receiving placebo over the course of the trial (Fig. 4B). The 3 and $10 \mathrm{mg}$ cohorts had significantly increased serum concentrations of IL-13 over time when compared to Visit 2 (pre-Dose 1) (3 mg, spearman $r=0.4193, p=0.0263 ; 10 \mathrm{mg}$, spearman $r=0.3708, p=0.0260$, non-parametric correlation of linear regression) (Fig. 4C and D). A significant increase was observed in both cohorts after only 4 weeks of dosing using an unpaired $t$-test. Interestingly, there was a significant decrease in the serum IL-13 concentration in the $30 \mathrm{mg}$ ( $p=0.0114$; unpaired $t$-test) and $60 \mathrm{mg}$ cohorts ( $p=0.0361$; unpaired $t$-test) between Visit 2 (pre-Dose 1 ) and Visit 10 (pre-Dose 9) when compared to placebo (Fig. 4A). This correlates with similar findings observed in pre-clinical models that, at higher doses of PI-2301, there is a decrease in T-cell release of cytokines such as IL-3 and IL-13 (unpublished data). Similar trends were observed for IL-3, i.e., a significant increase in serum concentrations of IL-3 over time when compared to Visit 2 (pre-Dose 1) (10 mg, spearman $r=0.3372, p=0.0443$, non-parametric correlation of linear regression)) and MDC, i.e., a significant increase in serum concentrations of MDC over time when compared to Visit 2 (pre-Dose 1) (3 mg, spearman $r=0.4885, p=0.0084 ; 10 \mathrm{mg}$, spearman $r=0.4365, p=0.0078$, nonparametric correlation of linear regression) (Figs. 5 and 6). However, when applying a one-way analysis of variance using a Kruskal-Wallis multiple comparison test, data was not significant for both IL-3 and MDC. Subjects treated with $1 \mathrm{mg}$ of PI-2301 had little to no effect on these cytokines/chemokines.

The limited number of subjects per cohort only allowed us to identify a few markers of interest, i.e., IL-3, IL-13 and MDC, for which a trended changes in serum concentrations could be observed for subjects dosed with 3 and $10 \mathrm{mg}$ of PI-2301 as compared to placebo. Future studies will
A

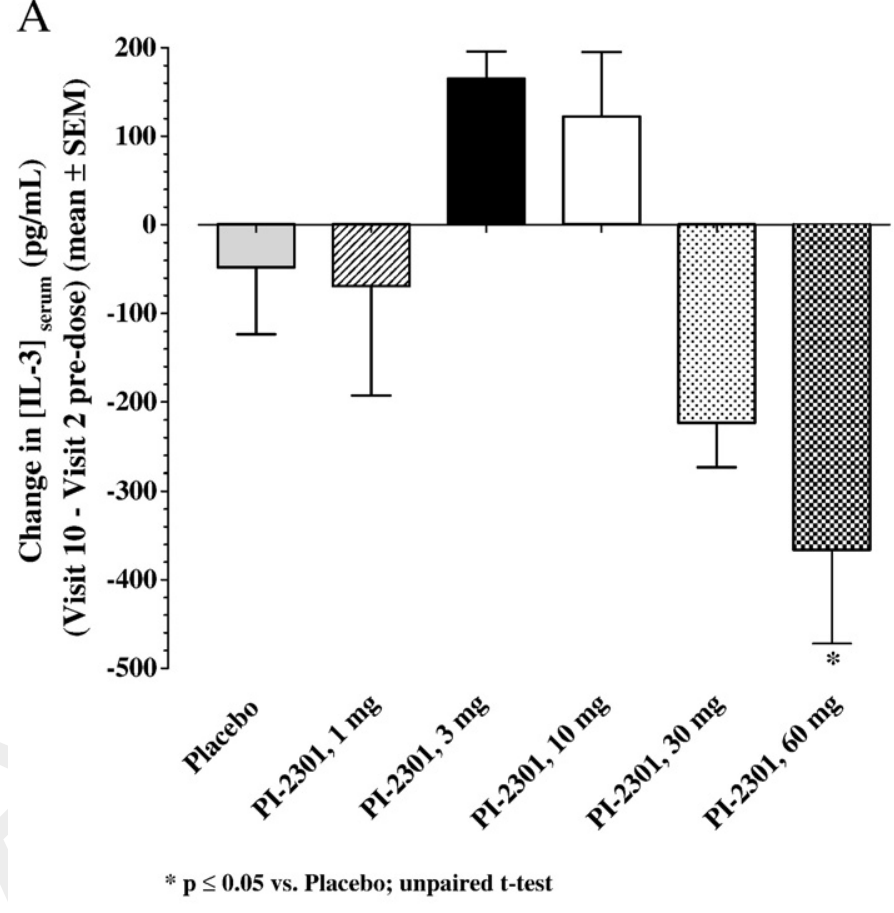

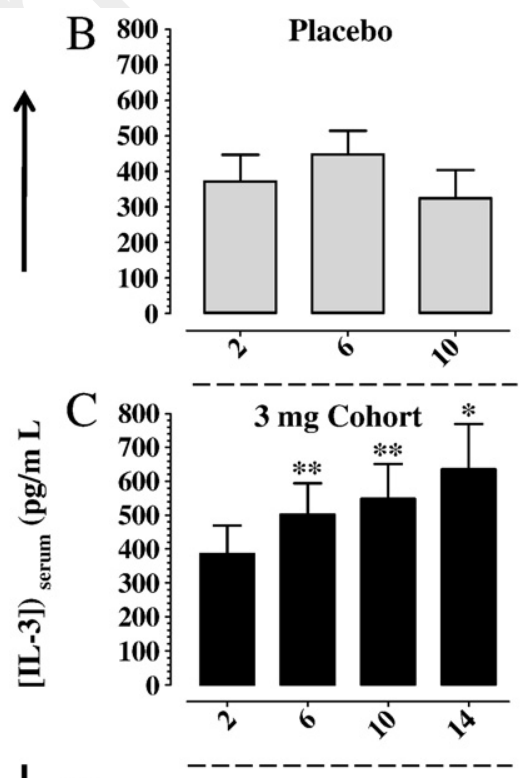

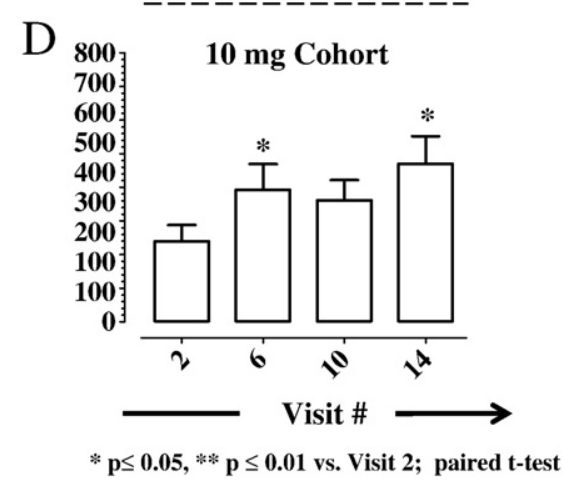

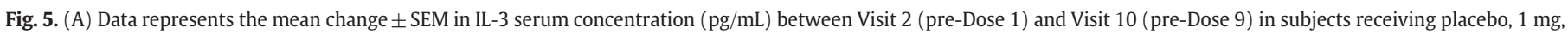

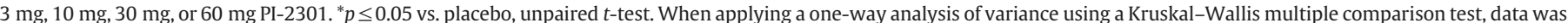

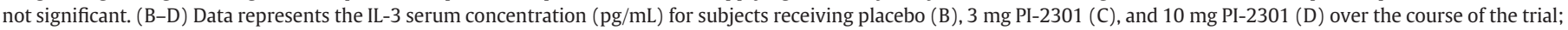

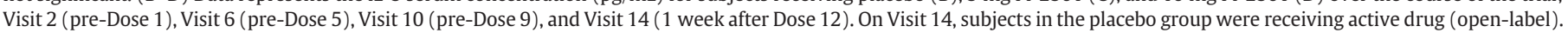
${ }^{*} p \leq 0.05,{ }^{* *} p \leq 0.01$ vs. Visit 2 (pre-Dose 1 ), paired $t$-test. 
A

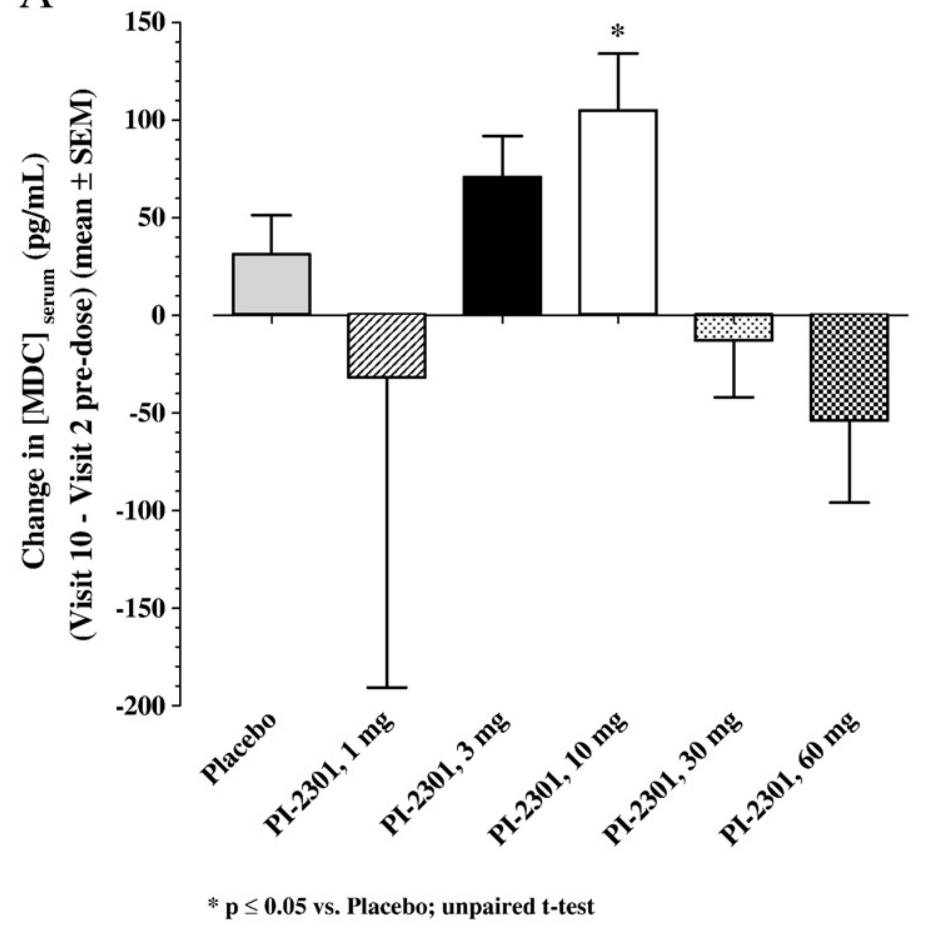

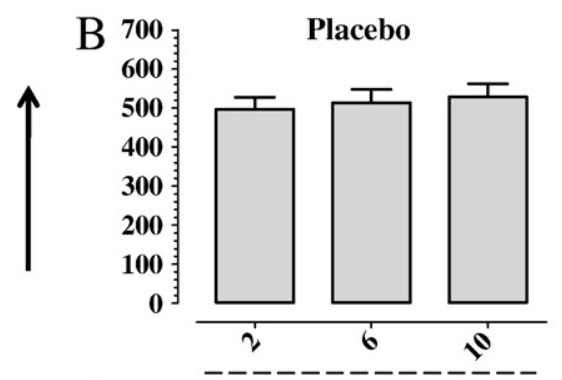
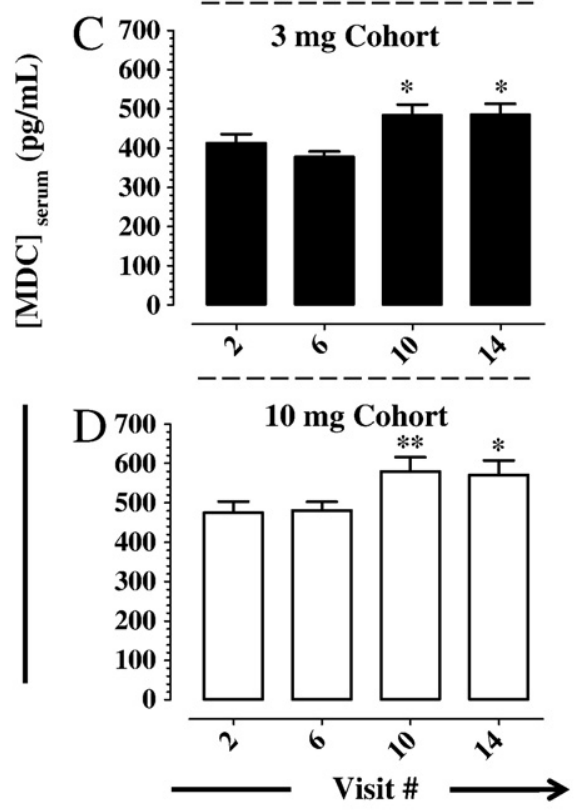

$* \mathbf{p} \leq 0.05, * * \mathbf{p} \leq 0.01$ vs. Visit 2; paired t-test

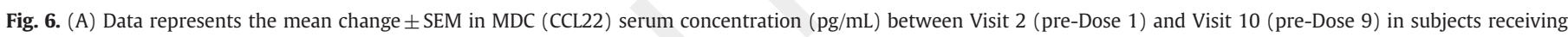

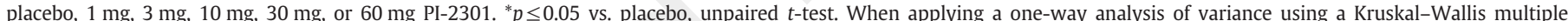

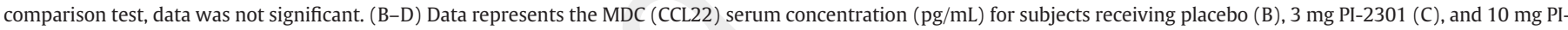

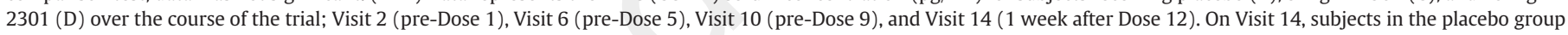
were receiving active drug (open-label). ${ }^{*} p \leq 0.05,{ }^{* *} p \leq 0.01$ vs. Visit 2 (pre-Dose 1 ), paired $t$-test.

extend these biomarker analyses to try to establish significant correlations between clinical efficacy and changes in these biomarkers.

Fig. 7 shows that administrations of PI-2301 at 30 and $60 \mathrm{mg}$ induced a significant increase in serum concentrations of MIP-1 beta ( $p=0.0275$ and $p=0.0340$ respectively; unpaired $t$-test) and MCP-1 ( $p=0.0249$ and $p=0.0153$ respectively; unpaired $t$-test) on Visit 2 (pre-Dose 1 and $4 \mathrm{~h}$ post Dose 1 ) when compared to placebo. There was no significant increase in either MIP- $1 \beta$ or MCP- 1 in the 1,3 , or $10 \mathrm{mg}$ cohorts. No evident trends were observed for serum markers IL-7, IL-8, IL-16, and IL-18 (data not shown).

\subsection{MRI lesions}

During the course of the trial, MRI gadolinium-enhanced T1 lesions were monitored on Visit 1 (initial screening visit), Visit 10 (Dose 9), and Visit 14 (1 week after Dose 12) (Fig. 8). Variations in the number of MRI lesions at the beginning of treatment were evident between the cohorts with subjects receiving placebo or $60 \mathrm{mg}$ PI-2301 having the fewest number of active lesions and subjects receiving $30 \mathrm{mg}$ PI-2301 having the greatest. It should be noted that 18 of the 50 subjects had no active MRI lesions over the course of the trial. A general trend was observed in the 1 and $3 \mathrm{mg}$ PI-2301 cohorts that showed a progressive decrease in the number of lesions over time. Subjects receiving placebo, 10,30 , or $60 \mathrm{mg}$ PI-2301 showed no clear trend. Similar results were observed when comparing total lesion volume (data not shown). Evaluation of subjects' EDSS scores showed no signs of worsening or improvement over the time course tested in all cohorts (data not shown).

\section{Discussion}

Although several therapies are currently approved to treat RR-MS, there remains an unmet medical need for new medications that improve efficacy, safety, and convenience for patients with RR-MS. There are also inadequate treatment options for patients with SP-MS. The data presented from the current study shows that PI-2301, an amino acid copolymer, is a safe immunomodulator and may become an interesting alternative to current therapies for RR-MS and SP-MS.

In this trial, PI-2301 was safe and generally well-tolerated. After SC weekly administration of PI-2301, the most frequent TEAEs for all PI-2301 treatment cohorts were mild to moderate transient ISRs that generally resolved spontaneously within a few hours after injection without any therapy. ISR incidence did increase as the dose of PI-2301 increased; however, severity did not increase over time as the subjects received multiple doses. These types of ISRs are consistent with our previous findings in a single ascending dose clinical trial in which healthy male volunteers received a single SC dose of PI-2301 (accepted manuscript Journal of Clinical Pharmacology). These results are also consistent with safety data obtained for other amino acid copolymers used in humans (Ziemssen et al., 2001).

No significant anti-PI-2301 antibody titers were observed in subjects receiving any dose of PI-2301, although anti-PI-2301 antibodies would 

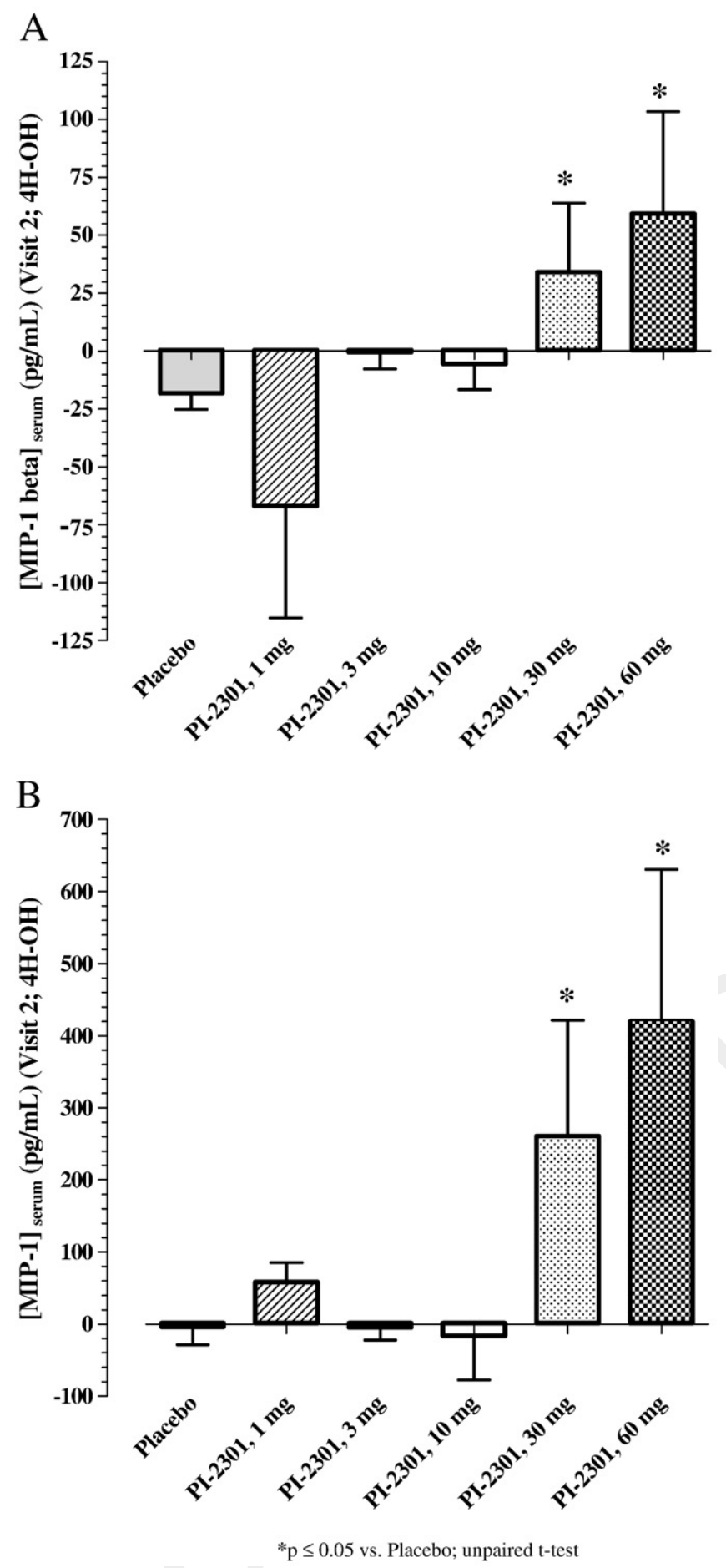

Fig. 7. Data represents a mean change \pm SEM in MIP-1 beta (A) or MCP-1 (B) serum concentration $(\mathrm{pg} / \mathrm{mL}$ ) between the 4 hour and 0 hour (pre-dose) time points on Visit 2 (Dose 1) in subjects receiving, $1 \mathrm{mg}, 3 \mathrm{mg}, 10 \mathrm{mg}, 30 \mathrm{mg}$, and $60 \mathrm{mg}$ PI-2301. * $p \leq 0.05$ vs. placebo, unpaired $t$-test.

probably not be neutralizing if they occurred. Copaxone-treated patients develop anti-compound antibodies; these antibodies are not neutralizing (Johnson et al., 1995). The lack of PI-2301 antibodies also reduces the chance of an anaphylactic reaction that may occur due to the induction of compound-specific IgE or IgG antibodies (Finkelman, 2007). There was also no significant difference in the numbers and relative percentages of PBMC analyzed during the course of this study, especially T-cell lymphocyte subsets. The cells were viable and the

numbers and percentages were within normal physiological range; the integrity of cells was preserved by both collection methods and transport modalities. PI-2301 has no immunosuppressive or deleterious effects on lymphocyte populations after several weekly administrations. Certain T-cell subpopulations could have been activated by PI-2301 without leading to cell expansion; however this activation process would have not been detected by the FACS analysis we used.

Analysis of pharmacodynamic markers suggests that PI-2301 has immunomodulatory properties. Cytokines and chemokines such as IL-3, IL-13, and MDC were released in response to PI-2301. Subjects that received 3 and $10 \mathrm{mg}$ of PI-2301 had increased serum levels of IL-3, IL-13, and MDC when compared to placebo. Doses of PI-2301 below $3 \mathrm{mg}$ or doses greater than $10 \mathrm{mg}$ did not release these cytokines or chemokines, suggesting a therapeutic dose window above $1 \mathrm{mg}$ and below $30 \mathrm{mg}$. It implies a U-shaped curve in terms of optimum response to PI-2301, similar to what has been observed in pre-clinical studies (unpublished observation). Although doses of PI-2301 at $30 \mathrm{mg}$ and higher will not be used in future clinical studies, at least in the current formulation, it was important to recapitulate in man the biomarker effect previously observed in animals. It validates our pharmacodynamic and pharmacokinetic efforts to define the optimum dose window to expect efficacy in future clinical studies; this translational medicine approach is in sharp contrast to the development of Copaxone ${ }^{\circledR}$ for which doses other than $20 \mathrm{mg}$ daily were never tested until recently and only after marketing approval by regulatory agencies.

IL-3, IL-13, and MDC increased over time in the 3 and $10 \mathrm{mg}$ cohorts. IL-3, IL-13, and MDC are known to be $\mathrm{T}_{\mathrm{H}} 2$ cytokines and chemokines (Andrew et al., 1998; Asquith et al., 2008). $\mathrm{T}_{\mathrm{H}} 2$ cytokines and chemokines have been shown to be beneficial for the treatment of MS (Columba-Cabezas et al., 2002; Sanna et al., 2006). It is thought that shifting the immune response from a $\mathrm{T}_{\mathrm{H}} 1$ to $\mathrm{a} \mathrm{T}_{\mathrm{H}} 2$ immune response is a critical part of the mechanism of action of amino acid copolymers (Illés et al., 2004; Stern et al., 2004). MDC is known to attract $\mathrm{T}_{\mathrm{H}} 2$ and regulatory T cells (Mantovani et al., 2004). $\mathrm{T}_{\mathrm{H}} 2$ cytokines such as IL-3 (Asquith et al., 2008) and IL-13 (Nakayama and Yamashita, 2008) function to promote dendritic cell (DC) survival/proliferation that preferentially induces a $\mathrm{T}_{\mathrm{H}} 2$ response (Ebner et al., 2002) and inhibits polarization and stimulation of $\mathrm{T}_{\mathrm{H}} 17 \mathrm{~T}$ cells (Newcomb et al., 2009) respectively. Since auto-reactive $T_{H} 1$ and $T_{H} 17$ cells drive autoimmune diseases such as MS, restoring the balance of the immune system by activating a $\mathrm{T}_{\mathrm{H}} 2$ immune response should prevent disease progression (Mantovani et al., 2004). PI-2301 might be creating a positive feedback loop in which $\mathrm{T}_{\mathrm{H}} 2$ cells are recruited by MDC release and in turn, $\mathrm{T}_{\mathrm{H}} 2$ cells release IL-3 stimulating DCs to activate more $\mathrm{T}_{\mathrm{H}} 2$ cells. The release of IL-13 from $\mathrm{T}_{\mathrm{H}} 2$ T cells would inhibit the generation of $\mathrm{T}_{\mathrm{H}} 17$ cells and consequently reduces disease severity. IL-13 can polarize APCs such as macrophages to produce MDC (Mantovani et al., 2004). It may be possible to use PI-2301 for other autoimmune indications in which a $\mathrm{T}_{\mathrm{H}} 2$ immune response is favorable such as Crohn's disease and rheumatoid arthritis (Mantovani et al., 2004; Herman et al., 2008; Eri et al., 2008).

Monocyte activation was evident by the release of MDC in the 3 and $10 \mathrm{mg}$ cohorts; however, it was also evident by the release of MCP- 1 and MIP- $1 \beta$ in the 30 and 60 mg cohorts. MCP- 1 and MIP-1 $\beta$ were only elevated in these two cohorts, which occurred hours after the first administration. MCP- 1 and MIP- $1 \beta$ have both been shown to promote homeostasis or a $\mathrm{T}_{\mathrm{H}} 2$ immune response (Maurer and von Stebut, 2004; Gu et al., 2000; Deshmane et al., 2009). However, the acute activation of the innate immune response as opposed to the long acting activation as shown by MDC release may not be beneficial.

There is a need for surrogate markers of efficacy in MS and early identification of responders to a particular therapy is of great importance. Future Phase II and Phase III studies will address biomarker analysis in an attempt to establish correlations between clinical efficacy of PI-2301 and changes in relevant biomarkers.

Even though no effects were observed on EDSS, MRI data shows a trend for the reduction in the number of gadolinium-enhanced lesions 


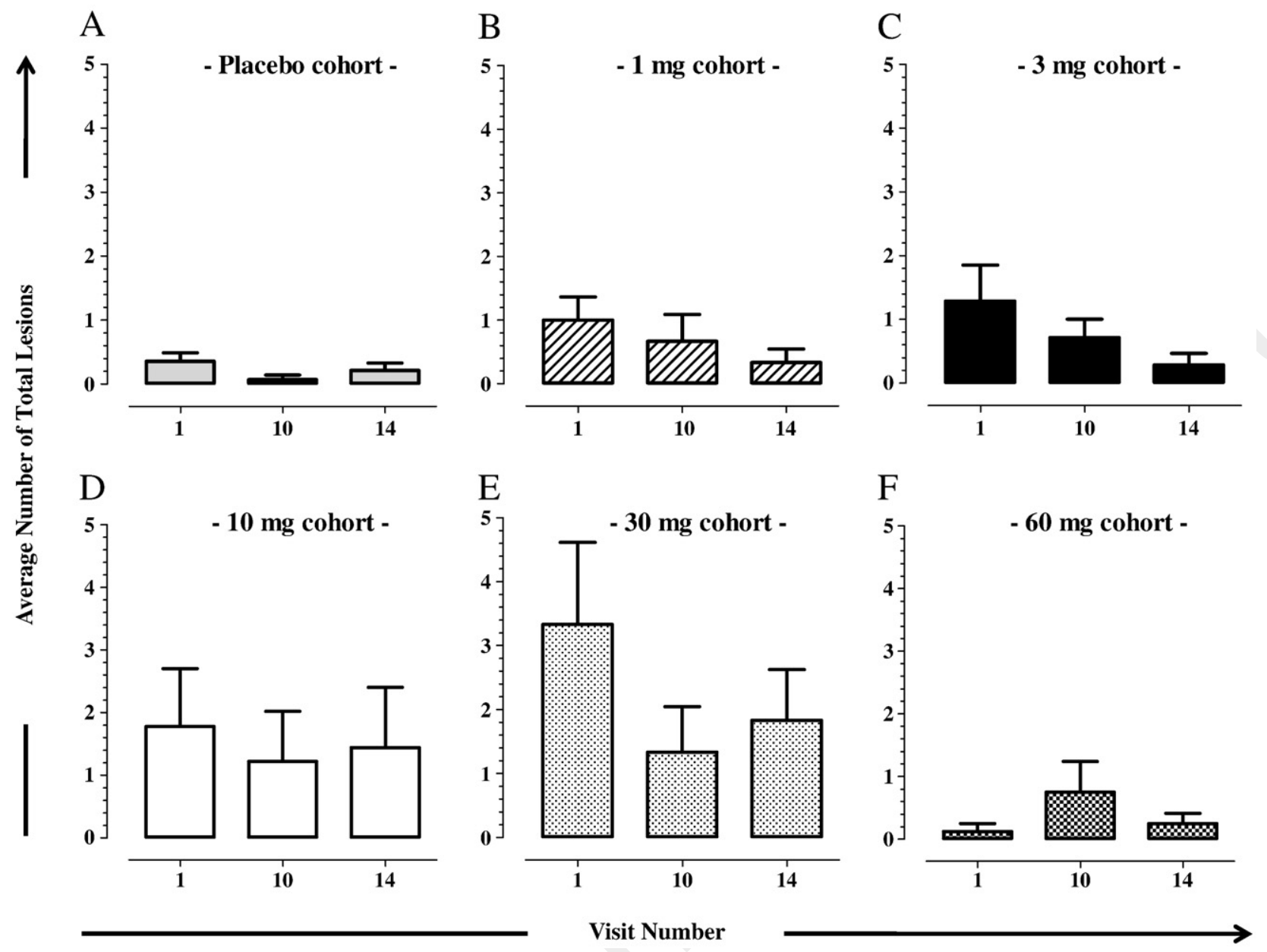

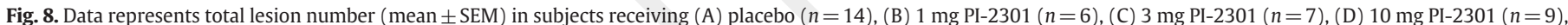

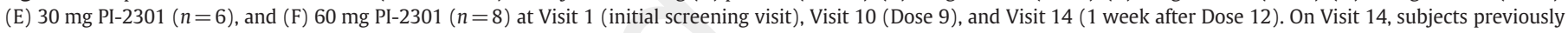
receiving placebo were receiving active drug (open-label).

in response to PI-2301 treatment in SP-MS patients at 1 and $3 \mathrm{mg}$. MRI data were not a conclusive endpoint parameter of the study; the sample size of the study was small, the number of subjects with active lesions between cohorts was not evenly distributed, and the duration of the study was short (12 weeks). However, the trend in MRI data suggests the potential benefit of PI-2301 for SP-MS patients, unlike interferon-beta which had no worsening effect on MRI lesions and no therapeutic effect in SP-MS patients (Inglese et al., 2003). In spite of their disease progression, SP-MS patients' immune system is still active and it may be possible to modulate it. Finally, PI-2301 might have an earlier onset of action than Copaxone ${ }^{\circledR}$, which takes at least 6 months to show efficacy in RR-MS patients (Comi et al., 2001; Wolinsky et al., 2002).

PI-2301 is capable of modulating an immune response with weekly dosing as opposed to daily dosing needed for Copaxone ${ }^{\circledR}$ (Ziemssen et al., 2001). PI-2301 seems more potent since doses as low as 3 or $10 \mathrm{mg}$ are capable of generating a favorable immune response as opposed to $20 \mathrm{mg}$ needed for Copaxone ${ }^{\circledR}$ (Ziemssen et al., 2001). Even though PI-2301 and Copaxone belong to the same compound class, their optimum therapeutic doses and treatment regimens might be quite different. These observations would be consistent with statements made by others on the fact that subtle changes in amino acid copolymer composition could have dramatic implications for their efficacy and safety (Varkony et al., 2009); thus, future amino acid copolymers, or even generic versions of approved amino acid copolymers, should be tested thoroughly in human clinical studies. Pharmacokinetic and pharmacodynamic parameter analyses, similar to the ones described in this manuscript, should be systematically implemented for the clinical development of future amino acid copolymers.

In conclusion, PI-2301 is a safe and generally well-tolerated immunomodulator. It does not appear to delete or suppress any compartments within the immune system and does not generate potential neutralizing antibodies against itself; these safety features make it very suitable for long term use in patients. PI-2301 at doses of 3 and $10 \mathrm{mg}$ may generate $\mathrm{a} \mathrm{T}_{\mathrm{H}} 2$ immune response as indicated by increases in serum concentrations of IL-3, IL-13, and MDC sometime as early as 4 weeks after initiation of weekly administration. MRI data suggests a reduction of lesion numbers in SP-MS patients treated with 1 and $3 \mathrm{mg}$ PI-2301. These findings are very encouraging and suggest that PI-2301 would have an early onset of efficacy in patients with RRMS or other autoimmune diseases. Phase II studies will soon be initiated to test this hypothesis.

\section{Acknowledgements}

The authors would like to acknowledge the essential contributions of Drs Bruno Brochet, Marc Debouverie, Gilles Defer, Jerome DeSeze, Jean Pelletier, Patrick Vermersch, Levente Kerenyi, Gabor Jakab, Gyula Panczel, Jelena Drulovic, Evica Dincic, and Gordana Toncev, all acting as principal investigators and without whom this study could not have been performed. We also thank Drs Alain Patat and Andre Paquin from Biotrial for their immense support with regulatory filings, protocol writing, and study management. Drs Mihaly Juhasz, Vid Stanulovic, and Jelisaveta Popovic-Gavrilov from Accelsiors were also 
essential partners in the submission and execution of this study in Hungary and Serbia. We are also grateful to Dr. Eric Lacoste, Dr. Stephane Bronner, and Claire Toutin from Avogadro for their technical expertise with the pharmacokinetic analysis.

\section{References}

Andrew, D.P., Chang, M., McNinch, J., Wathen, S.T., Rihanek, M., Tseng, J., Spellberg, J.P. Elias III, C.G., 1998. STCP-1 (MDC) CC chemokine acts specifically on chronically activated Th2 lymphocytes and is produced by monocytes on stimulation with Th2 cytokines IL-4 and IL-13. J. Immunol. 161, 5027-5038.

Asquith, K.L., Ramshaw, H.S., Hansbro, P.M., Beagley, K.W., Lopez, A.F., Foster, P.S., 2008. The IL-3/IL-5/GM-CSF common receptor plays a pivotal role in the regulation of the Th2 immunity and allergic airway inflammation. J. Immunol. 180, 1199-1206.

Bargagli, E., Mazzi, A., Mezzasalma, F., Perrone, A., Olivieri, C., Prasse, A., Bianchi, N., Pieroni, M.G., Rottoli, P., 2009. The analysis of tryptase in serum of sarcoidosis patients. Inflammation 32, 310-314.

Boggild, M., 2009. Immunosuppression followed by immunomodulation. J. Neurol. Sci. 277, S50-S54

Columba-Cabezas, S., Serafini, B., Ambrosini, E., Sanchez, M., Penna, G., Adorini, L., Aloisi, F., 2002. Induction of macrophage-derived chemokine/CCL22 expression in experimental autoimmune encephalomyelitis and cultured microglia: implications for disease regulation. J. Neuroimmunol. 130, 10-21.

Comi, G., 2009. Treatment of multiple sclerosis: role of natalizumab. Neurol. Sci. 30 S155-S158

Comi, G., Filippi, M., Wolinsky, J.S., 2001. European/Canadian multicenter, double-blind randomized, placebo-controlled study of the effects of glatiramer acetate on magnetic resonance imaging-measured disease activity and burden in patients with relapsing multiple sclerosis. European/Canadian Glatiramer Acetate Study Group. Ann. Neurol. 49, 290-297.

De Stefano, N., Filippi, M., Confavreux, C., Vermersch, P., Simu, M., Sindic, C., Hupperts, R., Bajenaru, O., Edan, G., Grimaldi, L., Marginean, I., Medaer, R., Orefice, G., Pascu, I, Pelletier, J., Sanders, E., Scarpini, E., Mancardi, G.L., 2009. The results of two multicenter, open-label studies assessing efficacy, tolerability and safety of protiramer, a high molecular weight synthetic copolymeric mixture, in patients with relapsing-remitting multiple sclerosis. Mult. Scler. 15, 238-243.

Deshmane, S.L., Kremlev, S., Amini, S., Sawaya, B.E., 2009. Monocyte chemoattractant protein 1 (MCP-1): an overview. J. Interferon Cytokine Res. 29, 313-326.

Dhib-Jalbut, S., 2003. Glatiramer acetate (Copaxone $\left.{ }^{\circledR}\right)$ therapy for multiple sclerosis. Pharmacol. Ther. 98, 245-255.

Dressel, A., Mirowska-Guzel, D., Gerlach, C., Wber, F., 2007. Migration of T-cell subsets in multiple sclerosis and the effect of interferon-beta1a. Acta Neurol. Scand. 116, $164-168$.

Ebner, S., Hofer, S., Nguyen, V.A., Furhapter, C., Herold, M., Fritsch, P., Heufler, C. Romani, N., 2002. A novel role for IL-3: human monocytes cultured in the presence of IL-3 and IL-4 differentiate into dendritic cells that produce less IL-12 and shift Th cell responses toward a Th2 cytokine pattern. J. Immunol. 168, 6199-6207.

Eri, R., Kodumudi, K.N., Summerlin, D.J., Srinivasan, M., 2008. Suppression of colon inflammation by CD 80 blockade: evaluation in two murine models of inflammatory bowel disease. Inflamm. Bowel Dis. 14, 458-470.

Finkelman, F.D., 2007. Anaphylaxis: lessons from mouse models. J. Allergy Clin. Immunol. 120, 506-515.

Fridkis-Hareli, M., Teitelbaum, D., Gurevich, E., Pecht, I., Brautbar, C., Kwon, O.J., Brenner, T., Arnon, R., Sela, M., 1994. Direct binding of myelin basic protein and synthetic copolymer 1 to class II major histocompatibility complex molecules on living antigenpresenting cells-specificity and promiscuity. Proc. Natl. Acad. Sci. U. S. A. 91, 4872-4876.

Fridkis-Hareli, M., Santambrogio, L., Stern, J.N.H., Fugger, L., Brosnan, C., Strominger, J.L. 2002. Novel synthetic amino acid copolymers that inhibit autoantigen-specfic $T$ cel responses and suppress experimental autoimmune encephalomyelitis. J. Clin. Investig. $109,1635-1643$.

Gauthier, L., Smith, K.J., Pyrdol, J., Kalandadze, A., Strominger, J.L., Wiley, D.C. Wucherpfennig, K.W., 1998. Expression and crystallization of the complex HLADR2 (DRA, DRB1*1501) and an immunodominant peptide of human myelin basic protein. Proc. Natl. Acad. Sci. U. S. A. 95, 11,828-11,833
Gu, L., Tseng, S., Horner, R.M., Tam, C., Loda, M., Rollins, B.J., 2000. Control of TH2 polarization by the chemokine monocyte chemoattractant protein-1. Nature 404 , 407-411.

Herman, S., Zurgil, N., Langevitz, P., Ehrenfeld, M., Deutsch, M., 2008. Methotrexate selectively modulates TH1/TH2 balance in active rheumatoid arthritis patients. Clin. Exp. Rheumatol. 26, 317-323.

Illés, Z., Stern, J.N.H., Reddy, J., Waldner, H., Mycko, M.P., Brosnan, C.F., Ellmerich, S., Altmann, D.M. Santambrogio, L, Strominger, J.L., Kuchroo, V.K., 2004. Modified amino acid copolymers suppress myelin basic protein 85-99-induced encephalomyelitis in humanized mice through different effects on T cells. Proc. Natl. Acad. Sci. U. S. A. 101, $11,749-11,754$

Inglese, M., van Waesberghe, J.H., Rovaris, M., Beckmann, K., Barkhof, F., Hahn, D., Kappos, L., Miller, D.H., Polman, C., Pozzilli, C., Thompson, A.J., Yousry, T.A., Wagner, K., Comi, G., Filippi, M., 2003. The effect of interferon beta-1b on quantities derived from MT MRI in secondary progressive MS. Neurology 60, 853-860.

Jarius, S., Hohlfeld, R., Voltz, R., 2003. Diagnosis and treatment of multiple sclerosis. Update, 2003. M.M.W. Fortschr. Med. 145, 88-91, 93, 95.

Johnson, K.P., Brooks, B.R., Cohen, J.A., Ford, C.C., Goldstein, J., Lisak, R.P., Myers, L.W., Panitch, H.S., Rose, J.W., Schiffer, R.B., 1995. Copolymer 1 reduces relapse rate and improves disability in relapsing-remitting multiple sclerosis: results of a phase III multicenter, double-blind placebo-controlled trial. The Copolymer 1 Multiple Sclerosis Study Group. Neurology 45, 1268-1276.

Mantovani, A., Sica, A., Sozzani, S., Allavena, P., Vecchi, A., Locati, M., 2004. The chemokine system in diverse forms of macrophage activation and polarization. Trends Immunol. 25, 677-686.

Martinelli, V., Radaelli, M., Straffi, L., Rodegher, M., Comi, G., 2009. Mitoxantrone: benefits and risks in multiple sclerosis patients. Neurol. Sci. 30, S167-S170.

Maurer, M., von Stebut, E., 2004. Macrophage inflammatory protein-1. Int. J. Biochem. Cell Biol. 36, 1882-1886.

Miller, A., Shapiro, S., Gershtein, R., Kinarty, A., Rawashdeh, H., Honigman, S., Lahat, N., 1998. Treatment of multiple sclerosis with copolymer-1 (Copaxone): implicating mechanisms of Th1 to Th2/Th3 immune-deviation. J. Neuroimmunol. 92, 113-121.

Nakayama, T., Yamashita, M., 2008. Initiation and maintenance of Th2 cell identity. Curr. Opin. Immunol. 20, 265-271.

Newcomb, D.C., Zhou, W., Moore, M.L., Goleniewska, K., Hershey, G.K.K., Kolls, J.K., Peebles Jr., R.S., 2009. A functional IL-13 receptor is expressed on polarized murine CD4 ${ }^{+}$Th17 cells and IL-13 signaling attenuates Th17 cytokine production. J. Immunol. 182, 5317-5321.

Papeix, C., Lubetzki, C., 2009. Monoclonal antibodies in multiple sclerosis. Med. Sci. (Paris) 25, 1113-1115.

Prat, A., Biernacki, K., Antel, J.P., 2005. Th1 and Th2 lymphocyte migration across the human $\mathrm{BBB}$ is specifically regulated by interferon beta and copolymer-1. J. Autoimmun. 24, 119-124.

Saito, H., Kato, A., Matsumoto, K., 2009. Role of mast cells in allergy. Nippon Rinsho 67, 2083-2087.

Sanna, A., Fois, M.L., Arru, G., Huang, Y.M., Link, H., Pugliatti, M., Rosati, G., Sotgiu, S., 2006. Glatiramer acetate reduces lymphocyte proliferation and enhances IL-5 ad IL-13 production through modulation of monocyte-derived dendritic cells in multiple sclerosis. Clin. Exp. Immunol. 143, 357-362.

Stern, J.N.H., Illés, Z , Reddy, J., Keskin, D.B., Sheu, E., Fridkis-Hareli, M., Nishimura, $H$. Brosnan, C.F., Santambrogio, L., Kuchroo, V.K., Strominger, J.L., 2004. Amelioration of proteolipid protein 139-151-induces encephalomyelitis in SJL mice by modified amino acid copolymers and their mechanisms. Proc. Natl. Acad. Sci. U. S. A. 101, $11,743-11,748$.

Teitelbaum, D., Meshorer, A., Hirshfeld, T., Arnon, R., Sela, M., 1971. Suppression of experimental allergic encephalomyelitis by a synthetic polypeptide. Eur.J. Immunol. 1, 242-248.

Varkony, H., Weinstein, V., Klinger, E., Sterling, J., Cooperman, H., Komlosh, T., Ladkani, D., Schwartz, R., 2009. The glatiramoid class of immunomodulator drugs. Expert Opin. Pharmacother. 10, 657-668.

Wolinsky, J.S., Comi, G., Filippi, M., Ladkani, D., Kadosh, S., Shifroni, G., 2002. Copaxone's effect on MRI-monitored disease in relapsing MS is reproducible and sustained. Neurology 59, 1284-1286.

Ziemssen, T., Neuhaus, O., Hohlfeld, R., 2001. Risk-benefit assessment of glatiramer acetate in multiple sclerosis. Drug Saf. 24, 979-990. 